\title{
Osthole induces apoptosis and suppresses proliferation via the PI3K/Akt pathway in intrahepatic cholangiocarcinoma
}

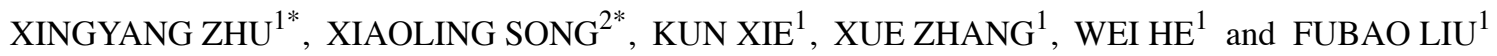 \\ ${ }^{1}$ Department of General Surgery, The First Affiliated Hospital of Medical University of Anhui, Hefei, Anhui 230022; \\ ${ }^{2}$ Department of Cardiothoracic Surgery, Xinhua Hospital Affiliated to Shanghai Jiao Tong University
}

School of Medicine, Shanghai 200082, P.R. China

Received January 9, 2017; Accepted July 28, 2017

DOI: $10.3892 / \mathrm{ijmm} .2017 .3113$

\begin{abstract}
Osthole is a natural coumarin isolated from Umbelliferae plant monomers. Previous research has indicated that osthole exerts a wide variety of biological effects, acting as anti-seizure, anti-osteoporosis and anti-inflammation. However, the regulatory effect and related molecular mechanism of osthole in intrahepatic cholangiocarcinoma (ICC) remain unknown. In the present study, the authors found that osthole inhibited ICC cell lines in a dose- and time-dependent manner. Osthole also significantly induced mitochondrialdependent apoptosis by upregulating Bax, cleaved caspase-3, cleaved caspase-9, and cleaved poly ADP-ribose polymerase expression, and by downregulating $\mathrm{Bcl}-2$ expression. Moreover, the levels of p-Akt and PI3K were significantly decreased, while total Akt protein levels were unchanged. Following transfection with wild-type-Akt and constitutively active (CA)-Akt plasmids, the effects of osthole were decreased. Osthole was also able to suppress tumor growth in vivo. Together, these data demonstrated that osthole induces mitochondrial-dependent apoptosis via the PI3K/Akt pathway, suggesting that osthole may represent a novel and effective agent for the treatment of ICC.
\end{abstract}

\section{Introduction}

Intrahepatic cholangiocarcinoma (ICC) is an epithelial cell malignancy arising from cells located proximal to the seconddegree bile ducts (1). The worldwide incidence of ICC seems to be increasing, although this pattern is not universal $(2,3)$.

Correspondence to: Professor Fubao Liu, Department of General Surgery, The First Affiliated Hospital of Medical University of Anhui, 218 Jixi Road, Hefei, Anhui 230022, P.R. China

E-mail: nsifhfisty112@163.com

${ }^{*}$ Contributed equally

Key words: osthole, intrahepatic cholangiocarcinoma, cancer, apoptosis, PI3K/Akt pathway
There is no effective adjuvant therapy, and surgical resection is the only potential curative treatment for ICC. Unfortunately, the long-term outcome for ICC remains dismal due to a high incidence of postoperative tumor recurrence and metastasis (4). The prognosis of ICC patients is poor, with a 5-year survival rate of only $25-35 \%$ in most studies (5-7). Thus, there is a significant need to develop effective therapeutic strategies that can improve the prognosis of ICC patients.

Accumulating evidence suggests that medicinal plants are a significant source of potential agents against cancer (8-10). Osthole is a natural coumarin isolated from Umbelliferae plant monomers, and its chemical formula is $\mathrm{C}_{15} \mathrm{H}_{16} \mathrm{O}_{3}$. Osthole has been proven to exert a wide variety of biological effects, such as anti-seizure, anti-osteoporosis and anti-inflammation (11-13). Studies have confirmed that osthole can inhibit the growth and proliferation of various cancer cells through inducing apoptosis or cell cycle arrest $(14,15)$. Moreover, osthole can inhibit tumor metastasis by inhibiting the epithelial-mesenchymal transition process (16). However, the underlying mechanisms for the therapeutic effects of osthole remain unknown. In the present study, the authors explored the anticancer effects of osthole on ICC cells and investigated the potential mechanisms through which osthole mediates these effects.

\section{Materials and methods}

Reagents and drugs. Osthole was purchased from Sigma-Aldrich; Merck KGaA (Darmstadt, Germany) (Fig. 1A), dissolved in dimethyl sulfoxide (DMSO), and stored at $-20^{\circ} \mathrm{C}$. The final DMSO concentration used was $<0.1 \%$. The cell counting kit- 8 (CCK- 8 ), Hoechst 33342, and rhodamine 123 were purchased from SigmaAldrich; Merck KGaA. The Annexin V/propidium iodide (PI) apoptosis kit was purchased from Invitrogen; Thermo Fisher Scientific, Inc. (Waltham, MA, USA). All antibodies were purchased from Santa Cruz Biotechnology, Inc. (Dallas, TX, USA). All cell culture supplies were obtained from Gibco; Thermo Fisher Scientific, Inc.

Cell culture. The human ICC cell lines HCCC-9810 and RBE were purchased from the Cell Bank of the Type Culture Collection of the Chinese Academy of Sciences (Shanghai, China). Both HCCC-9810 and RBE cells were cultured in RPMI-1640 medium supplemented with $10 \mu \mathrm{g} / \mathrm{ml}$ strepto- 
mycin, $100 \mathrm{U} / \mathrm{ml}$ penicillin (HyClone; GE Healthcare Life Sciences, Logan, UT, USA), and $10 \%$ fetal bovine serum (Gibco; Thermo Fisher Scientific, Inc.). The cells were cultured at $37^{\circ} \mathrm{C}$ in a humidified incubator with $5 \% \mathrm{CO}_{2}$.

Cell viability assay. The effect of osthole on the viability of ICC cells was evaluated using the CCK-8 assay. HCCC9810 and RBE cells were seeded into 96-well culture plates at a density of 3,000 cells/well and cultured for $24 \mathrm{~h}$. Cells were treated with different concentrations of osthole $(0,25$, $50,100,150$ or $200 \mu \mathrm{M})$ for 24,48 or $72 \mathrm{~h}$. CCK-8 $(10 \mu \mathrm{l})$ was subsequently added to each well and incubated for $2 \mathrm{~h}$ in the dark. The absorbance of the plates was measured at $450 \mathrm{~nm}$ using a microplate reader (Bio-Tek Instruments, Inc., Norcross, GA, USA). Cell viability was calculated using the following formula: cell viability $=(O D$ of treated cells-OD of blank)/(OD of control-OD of blank) x100\%. The assay was repeated three times.

Colony formation assay. The ability of ICC cells to form clones was investigated using a colony formation assay. ICC cells were seeded into 6-well plates at a density of 600 cells/well. Various concentrations of osthole $(0,100$, 150 or $200 \mu \mathrm{M}$ ) were added for 14 consecutive days. Then, the cells were fixed with $10 \%$ formalin and stained with $0.1 \%$ crystal violet (Sigma-Aldrich; Merck KGaA) for visualization and counting. The colonies (groups of $>50$ cells) were observed under a microscope (Leica Microsystems $\mathrm{GmbH}$, Wetzlar, Germany).

Annexin V/PI staining assay for apoptosis. The apoptosis rate of ICC cells was determined using flow cytometric analysis. HCCC-9810 and RBE cells were treated with osthole $(0,100$, 150 or $200 \mu \mathrm{M}$ ) for $48 \mathrm{~h}$. Subsequently, attached and floating cells were collected and washed twice with phosphate-buffered saline (PBS). Following centrifugation $(500 \mathrm{x} \mathrm{g}$ for $5 \mathrm{~min}$ ), the cells were resuspended in $1 \mathrm{X}$ Annexin $\mathrm{V}$ binding buffer and incubated with $5 \mu 1$ Annexin $\mathrm{V}$ and $\mathrm{PI}$ at $37^{\circ} \mathrm{C}$ for $15 \mathrm{~min}$. Immediately following incubation, cell apoptosis was measured using flow cytometry.

Hoechst 33342 staining. RBE and HCCC-9810 cells were seeded into 6 -well plates and treated with osthole $(0,100$, 150 or $200 \mu \mathrm{M}$ ) for $48 \mathrm{~h}$. The cells were fixed with $1 \mathrm{ml}$ methanol/acetic acid (3:1) for $20 \mathrm{~min}$ at room temperature. The fixed cells were rinsed with PBS for 5 min prior to incubation with Hoechst $33342(5 \mu \mathrm{g} / \mathrm{ml})$ in the dark for $15 \mathrm{~min}$ at room temperature. Morphological changes were observed using a fluorescence microscope (Leica Microsystems $\mathrm{GmbH}$ ).

Mitochondrial membrane potential $(\Delta \Psi \mathrm{m})$. The cells were treated with various concentration of osthole $(0,100,150$ or $200 \mu \mathrm{M}$ ) for $48 \mathrm{~h}$. Then, attached and floating cells were collected and washed with PBS. Following centrifugation (500 x $\mathrm{g}$ for $5 \mathrm{~min}$ ), the cells were stained with rhodamine 123 in a $5 \% \mathrm{CO}_{2}$ incubator at $37^{\circ} \mathrm{C}$ for $20 \mathrm{~min}$ away from light. The samples were then analyzed by flow cytometry.

Western blot analysis. Western blot analysis was conducted as described previously (17). Total protein was extracted from cell samples using RIPA lysis buffer supplemented with protease inhibitor (both from Beyotime Institute of Biotechnology, Haimen, China). Protein concentration was measured using a BCA protein assay (Thermo Scientific, Rockford, IL, USA). Equal amounts of protein $(20 \mu \mathrm{g})$ were separated using $10 \%$ sodium dodecyl sulfate-polyacrylamide gel electrophoresis (SDS-PAGE) and transferred to polyvinylidene difluoride membranes. Following blocking in 5\% nonfat milk for $2 \mathrm{~h}$ at room temperature, the membranes were incubated with primary antibodies against Bcl-2 (1:1,000; 15071), Bax (1:1,000; 5023), caspase-9 (1:1,000; 9502), caspase-3 (1:1,000; 9662), PARP (1:1,000; 9532), cleaved caspase-9 (1:1,000; 20750), cleaved caspase-3 $(1: 1,000 ; 9661)$, cleaved PARP $(1: 1,000 ; 5625)$, PI3K $(1: 1,000 ; 4249)$, Akt $(1: 1,000 ; 2920)$ and p-Akt $(1: 1,000 ; 4060)$ (all from Cell Signaling Technology, Danvers, MA, USA) overnight at $4^{\circ} \mathrm{C}$. After incubation with a secondary antibody, immunocomplexes were visualized by enhanced chemiluminescence. Glyceraldehyde 3-phosphate dehydrogenase (GAPDH) $(1: 1,000 ; 5174$; Cell Signaling Technology) was used as an internal control to ensure equal protein loading. Proteins were observed using a Gel Doc 2000 with Quantity One 4.62 (Bio-Rad Laboratories, Inc., Hercules, CA, USA).

Plasmid transfection. Empty vector (pcDNA 3.1), wild-type mouse Akt (WT-Akt), and constitutively active (CA) mouse Akt (CA-Akt) overexpression plasmids were purchased from Era Biotech (Barcelona, Spain). ICC cells were transfected with these plasmids at $70-80 \%$ confluence using Viafect transfection reagent (Promega Corp., Madison, WI, USA), according to the manufacturer's protocol.

In vivo tumor xenograft study. Male nude mice (aged 4-6 weeks, weighing 18-22 g) were purchased from Shanghai SLAC Laboratory Animal Co., Ltd. (Shanghai, China). The animals were housed at $25 \pm 2^{\circ} \mathrm{C}$ at a relative humidity of $70 \pm 5 \%$ under natural light/dark conditions for 1 week and allowed free access to food and water. HCCC-9810 cells (at a density of $1 \times 10^{6}$ cells $/ 0.2 \mathrm{ml}$ corn oil) were injected into the right axilla of each mouse. At $24 \mathrm{~h}$ later, the mice were randomly divided into three groups (control, $50 \mathrm{mg} / \mathrm{kg}$ and $100 \mathrm{mg} / \mathrm{kg}$; $7 \mathrm{mice} /$ group). Mice in the control group were intraperitoneally injected with corn oil. The other groups received osthole (50 or $100 \mathrm{mg} / \mathrm{kg}$ ) every 2 days for up to 25 days. On day 26 , the animals were sacrificed, and the tumors were dissected and measured. The tumor volume was determined using the following formula: volume $=\left(\right.$ length $\mathrm{x}$ width $\left.{ }^{2}\right) / 2$. The animal experiments were performed in strict accordance with international ethical guidelines and the National Institutes of Health Guide for the Care and Use of Laboratory Animals (National Institutes of Health, Bethesda, MD, USA). The study protocol was approved by Laboratory Animal Ethics Committee of Anhui Medical University [LISC (Anhui) 20150336].

Statistical analysis. All experiments were performed at least three times, and the results are expressed as the means \pm standard deviations unless otherwise stated. Student's t-tests were used to compare differences between the treated groups and the corresponding control groups. $\mathrm{P}<0.05$ was considered to indicate a statistically significant difference. 
<smiles>COc1ccc2c(c1CC=C(C)C)OC(O)C=C2</smiles>
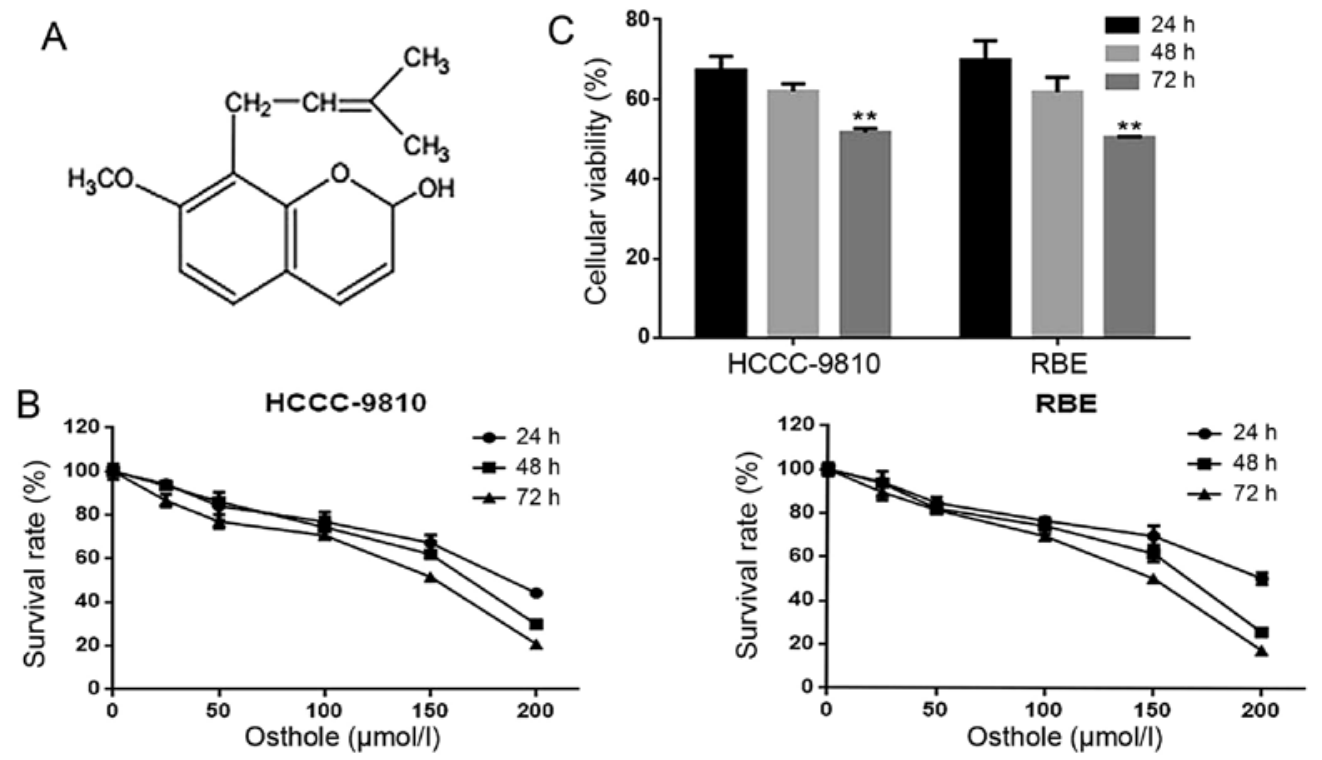

\begin{tabular}{lllll}
$D$ & 100 & 150 & 200 & $\mu \mathrm{mol} / \mathrm{l}$ \\
\hline
\end{tabular}
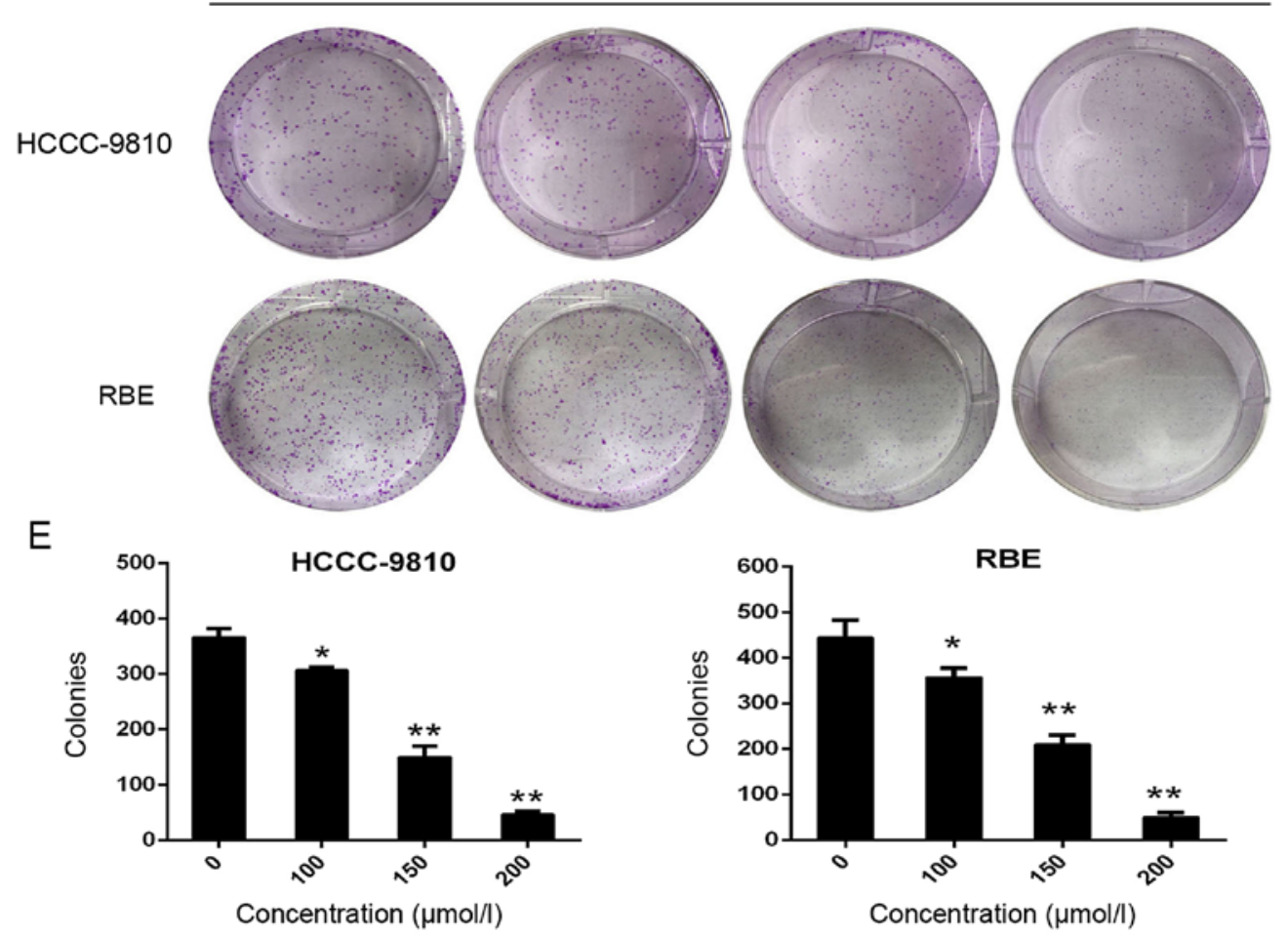

Figure 1. Osthole suppresses the viability and colony formation of intrahepatic cholangiocarcinoma (ICC) cells. (A) The chemical structure of osthole. (B) A cell counting kit-8 (CCK-8) assay was performed to analyze the viability of ICC cells treated with various concentrations of osthole $(0,25,50,100,150$ or $200 \mu \mathrm{M})$ for 24,48 or $72 \mathrm{~h}$. (C) ICC cells were treated with $150 \mu \mathrm{M}$ osthole for 24,48 or $72 \mathrm{~h}$. Then, cell viability was assessed using the CCK- 8 assay. (D and E) Cells were cultured with various concentrations of osthole $(0,25,50,100,150$ or $200 \mu \mathrm{M})$ and were allowed to form colonies for 14 days. ${ }^{*} \mathrm{P}<0.05$ and ${ }^{* *} \mathrm{P}<0.01 \mathrm{vs}$. control.

\section{Results}

Osthole inhibits the proliferation and viability of HCCC-9810 and RBE cells. The proliferation rates of the ICC cell lines HCCC-9810 and RBE were determined by CCK- 8 assay after the cells were treated with osthole at $0,25,50,100,150$ or $200 \mu \mathrm{M}$ for 24,48 and $72 \mathrm{~h}$. The results indicated that the proliferation of these ICC cell lines was inhibited by osthole in a dose- and time-dependent manner (Fig. $1 \mathrm{~B}$ and C). The $\mathrm{IC}_{50}$ of osthole in HCCC-9810 cells was $201 \mu \mathrm{M}(24 \mathrm{~h}), 159 \mu \mathrm{M}$ (48 h) and $131 \mu \mathrm{M}(72 \mathrm{~h})$; for RBE cells, the $\mathrm{IC}_{50}$ values were
$235 \mu \mathrm{M}(24 \mathrm{~h}), 153 \mu \mathrm{M}(48 \mathrm{~h})$ and $130 \mu \mathrm{M}(72 \mathrm{~h})$. As the required concentration of osthole for the $\mathrm{IC}_{50}$ at $48 \mathrm{~h}$ was much lower than that at $24 \mathrm{~h}$ and close to that at $72 \mathrm{~h}$, we only used the $48 \mathrm{~h}$ $\mathrm{IC}_{50}$ for subsequent experiments. Osthole also inhibited the ability of ICC cells to form clones, as shown in Fig. 1D and E. Following treatment with various concentrations $(0,100,150$ or $200 \mu \mathrm{M}$ ) for $\sim 2$ weeks, the number and size of the colonies derived from osthole-treated cells were markedly smaller than those of the colonies in the control group. These data indicated that osthole can inhibit the proliferation and viability of ICC cells. 
A

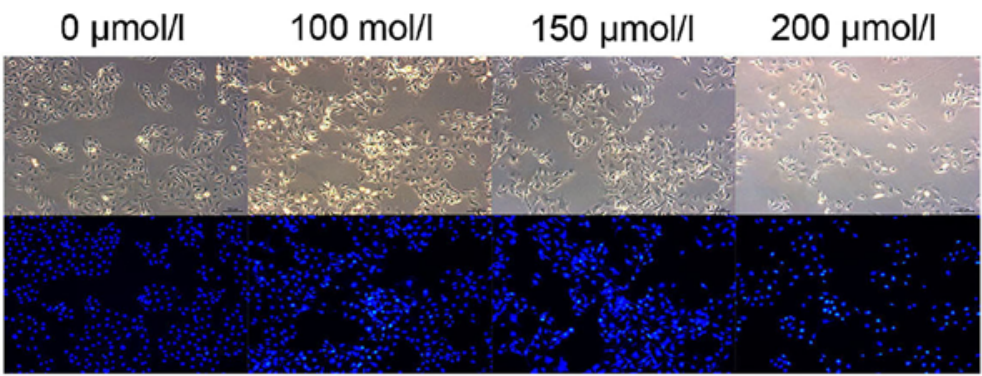

RBE

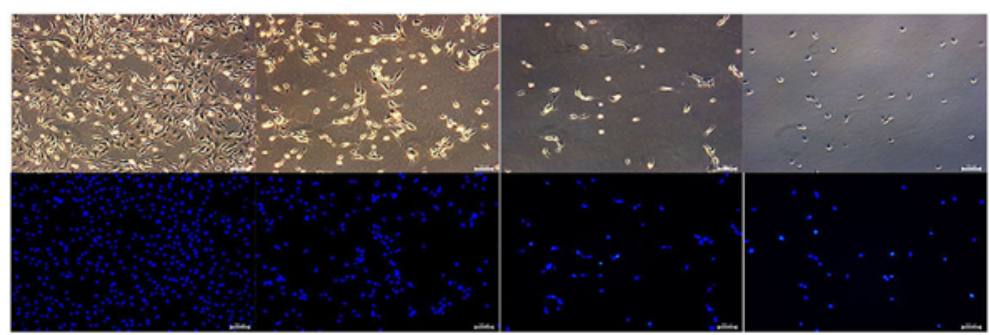

B

HCCC-9810

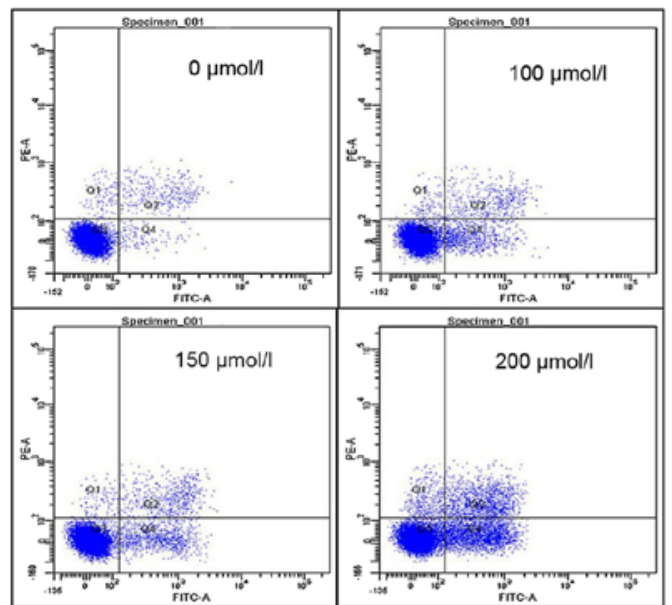

HCCC-9810

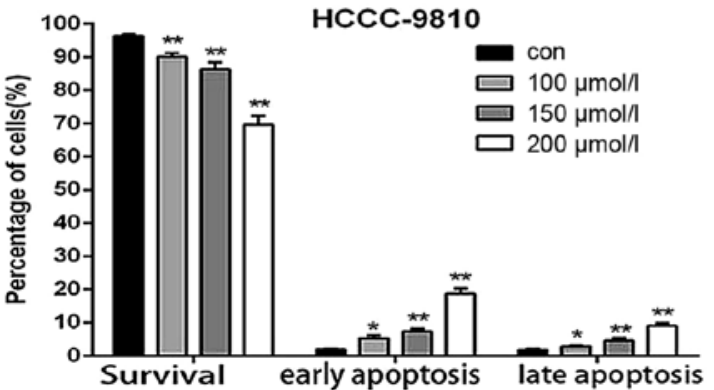

RBE
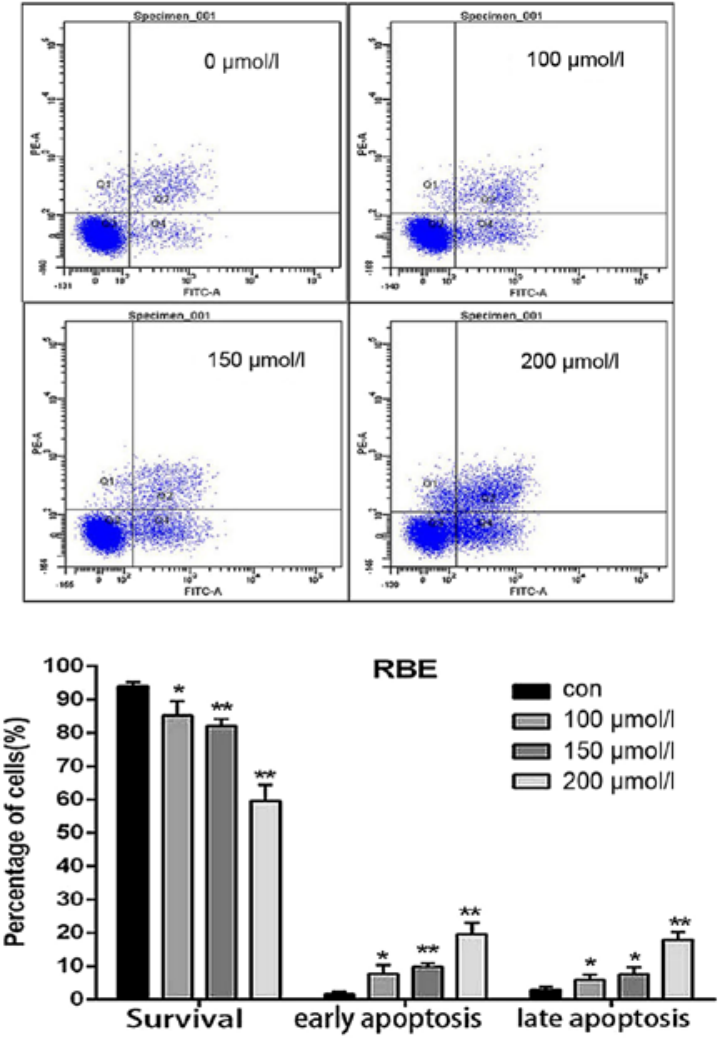

Figure 2. Osthole induces apoptosis in RBE and HCCC-9810 cells. (A) Intrahepatic cholangiocarcinoma (ICC) cells were treated with osthole for $48 \mathrm{~h}$ and then stained with Hoechst 33342. The morphological changes were observed using a fluorescence microscope. (B) RBE and HCCC-9810 cells were treated with osthole for $48 \mathrm{~h}$ and then stained with Annexin V/propidium iodide (PI). The apoptosis rate was evaluated by flow cytometry. The cells in early apoptosis (Q4 quadrant, Annexin $\mathrm{V}^{+} / \mathrm{PI}^{-}$) and late apoptosis (Q2 quadrant, Annexin $\mathrm{V}^{+} / \mathrm{PI}^{+}$) increased while the normal cells (Q3 quadrant, Annexin $\mathrm{V}^{-} / \mathrm{PI}$ ) decreased in a dose-dependent manner. ${ }^{*} \mathrm{P}<0.05$ and ${ }^{* *} \mathrm{P}<0.01$ vs. control.

Osthole induces mitochondria-dependent apoptosis. The effects of osthole on apoptosis were analyzed using flow cytometry and Hoechst 33342 staining in HCCC-9810 and RBE cells. We treated HCCC-9810 and RBE cells with a range of concentrations $(0,100,150$ or $200 \mu \mathrm{M})$ for $48 \mathrm{~h}$ and subsequently stained the cells with Hoechst 33342 . The cells treated with osthole exhibited markedly increased chromatin condensation and fragmentation compared to the cells in the control group, which were round and homogeneously stained (Fig. 2A). Next, we measured the apoptosis of ostholetreated cells by flow cytometry. Compared with the rates in the control group, the early and late apoptosis rates of cells treated with osthole significantly increased in a dose-dependent manner (Fig. 2B). These results indicate that osthole can induce apoptosis in HCCC-9810 and RBE cells.

Mitochondrial damage results in perturbation of the mitochondrial membrane potential $(\Delta \Psi \mathrm{m})(18)$. In this study, we measured the changes of $\Delta \Psi \mathrm{m}$ in ICC cells through rhoda- 
A
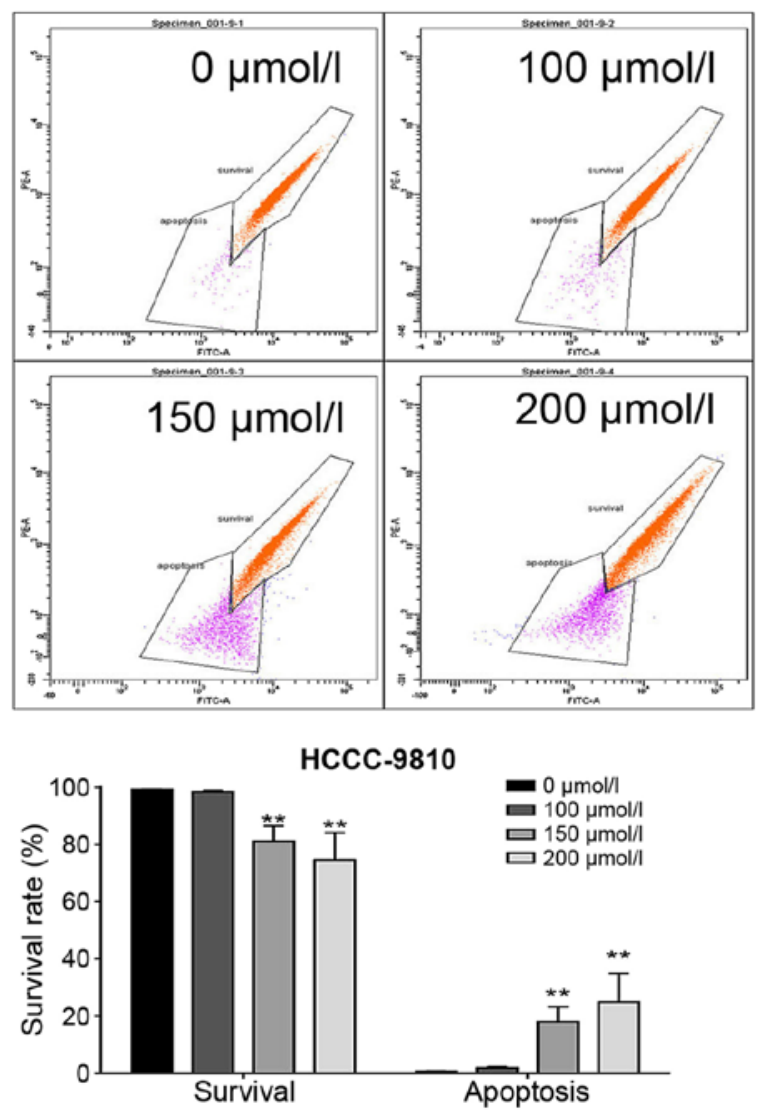
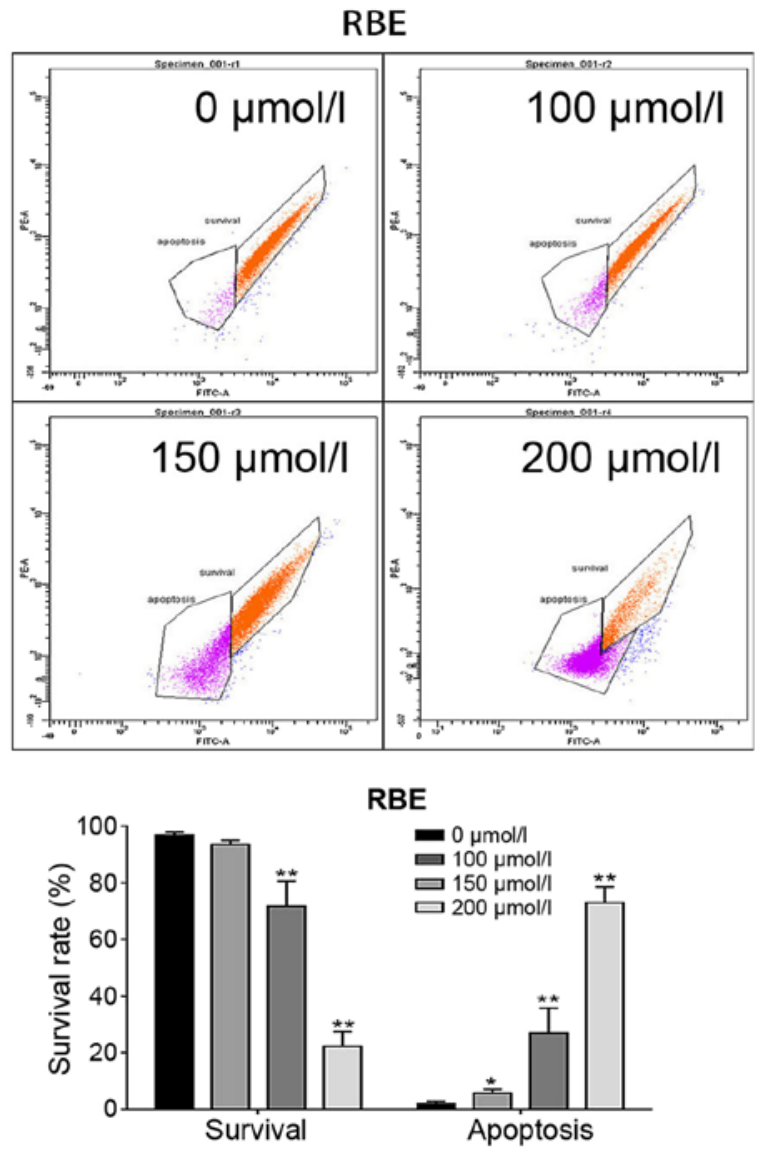

RBE

B
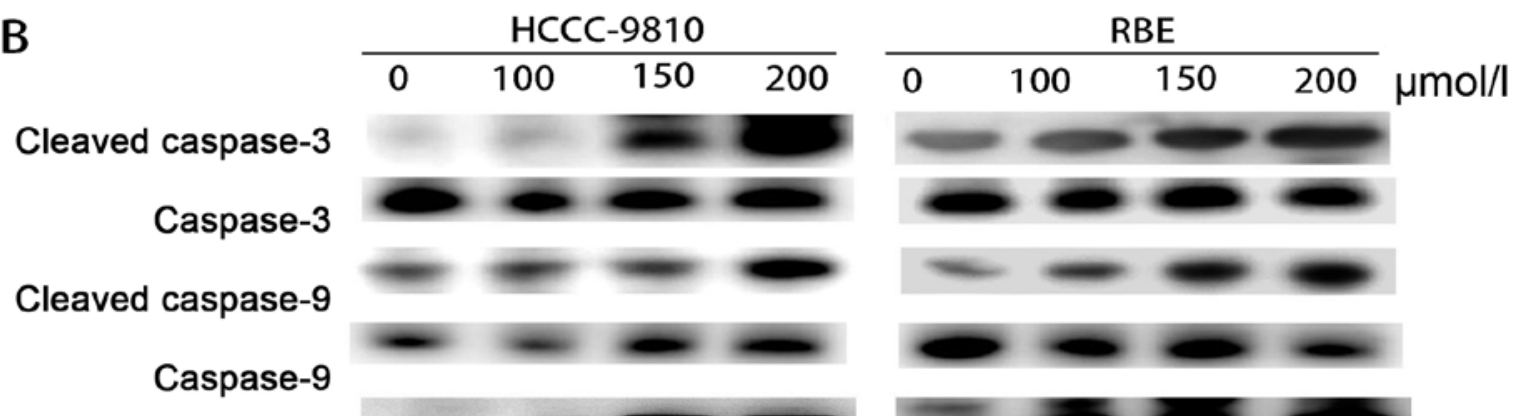

Cleaved PARP

Bcl-2

Bax

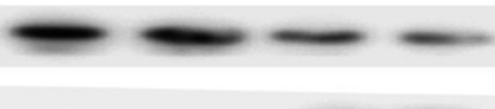

GAPDH

Figure 3. Osthole induces mitochondrial-dependent apoptosis in RBE and HCCC-9810 cells. (A) The mitochondrial membrane potential ( $\Delta \Psi \mathrm{m}) \mathrm{was}$ measured using flow cytometric analysis. RBE and HCCC-9810 cells were treated with osthole $(0,50,150$ or $200 \mu \mathrm{M})$ and then stained with rhodamine 123 . Cells with high $\Delta \Psi \mathrm{m}$ are marked 'survival', and those with low $\Delta \Psi \mathrm{m}$ are marked 'apoptosis'. (B) Apoptosis-related proteins in RBE and HCCC-9810 cells were analyzed by western blotting. GAPDH was used as a loading control. ${ }^{*} \mathrm{P}<0.05$ and ${ }^{* *} \mathrm{P}<0.01$ vs. control.

mine 123 staining using a flow cytometer. As shown in Fig. 3A, $\Delta \Psi \mathrm{m}$ decreased in a dose-dependent manner, indicating that osthole induced mitochondria-dependent apoptosis.

To explore the potential mechanism of osthole-induced apoptosis, the relative levels of key apoptosis-related proteins were evaluated by western blot analysis. As presented in Fig. 3B, the expression level of the mitochondrial anti-apoptotic protein Bcl-2 was significantly decreased, while the expression levels of pro-apoptotic factors including Bax and the cleaved forms of caspase-3, caspase-9 and PARP were upregulated. These results indicated that osthole induces mitochondria-dependent apoptosis in HCCC-9810 and RBE cells.

PI3K/Akt signaling pathway is involved in the apoptosis induced by osthole. In addition, the authors also investigated the expression levels of PI3K and Akt. As presented in Fig. 4A, 
A

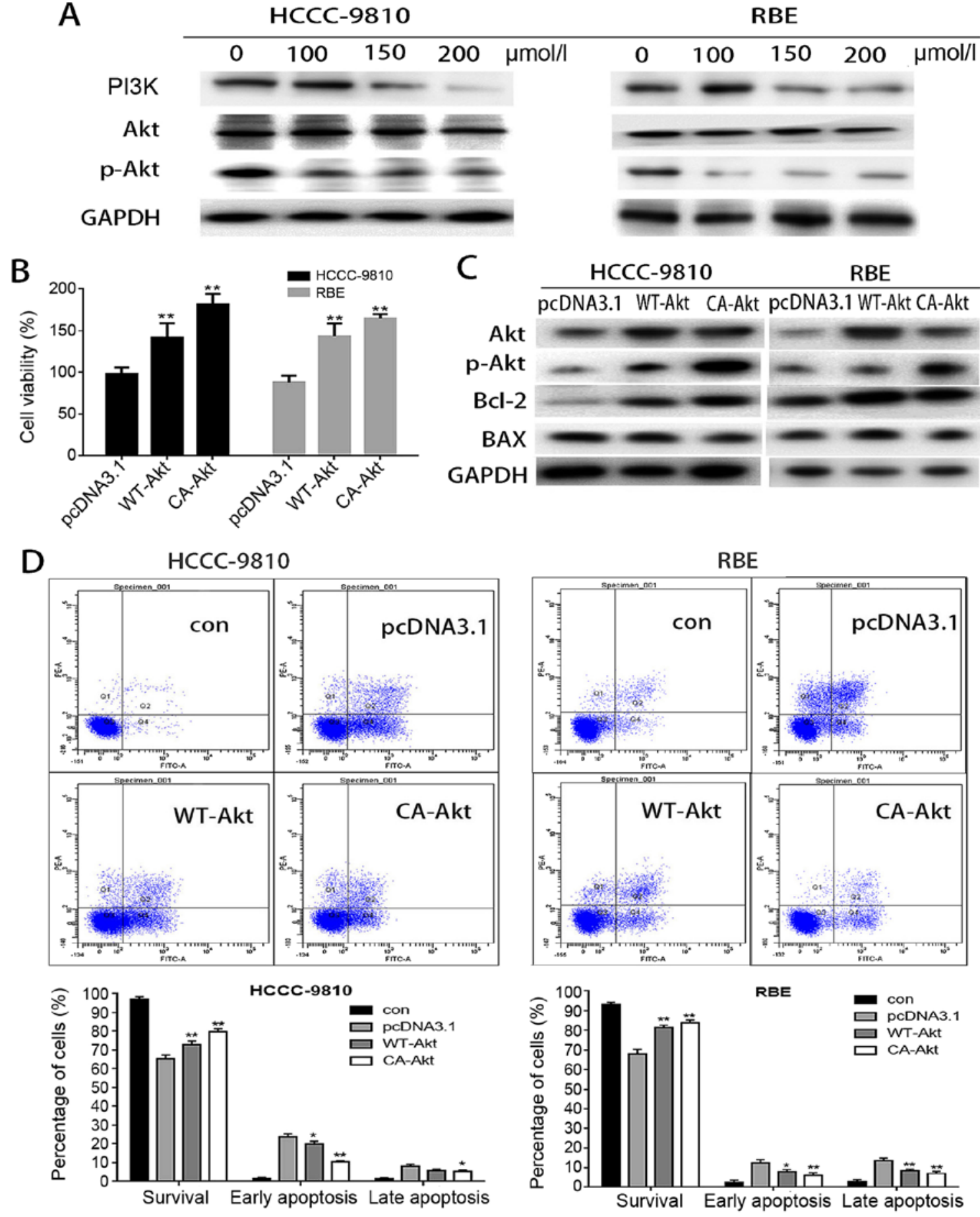

Figure 4. The PI3K/Akt pathway is involved in the apoptosis induced by osthole in intrahepatic cholangiocarcinoma (ICC) cells. (A) RBE and HCCC-9810 cells were treated with osthole $(0,50,100$ or $150 \mu \mathrm{M})$ for $48 \mathrm{~h}$, and the expression levels of p-PI3K, Akt and p-Akt were measured by western blot assays. GAPDH was used as a loading control. (B) Cellular viability was determined after treatment with $150 \mu \mathrm{M}$ osthole for $48 \mathrm{~h}$ in cells transfected with wild-type (WT)-Akt, constitutively active (CA)-Akt or vehicle plasmid. (C) The expression levels of Akt, p-Akt, Bcl-2 and Bax were evaluated by western blotting, and GAPDH was used as a loading control. (D) The apoptosis rate was evaluated by flow cytometry after treatment with $150 \mu \mathrm{M}$ osthole in cells transfected with WT-Akt, CA-Akt or vehicle plasmid. ${ }^{*} \mathrm{P}<0.05$ and ${ }^{* *} \mathrm{P}<0.01$ vs. control.

the levels of p-Akt and PI3K were significantly decreased, while the levels of Akt reported no obvious change. These results indicated that the $\mathrm{PI} 3 \mathrm{~K} / \mathrm{Akt}$ signaling pathway is involved in the anticancer effects of osthole.

Tofurther determine whether osthole-induced apoptosis was mediated by inhibition of Akt activity, the authors transiently transfected WT-Akt and CA-Akt plasmids into HCCC-9810 and RBE cells, treated the cells with osthole, and evaluated cell viability. As reported in Fig. 4B, overexpression of WT-Akt or CA-Akt abolished osthole cytotoxicity in HCCC-9810 and $\mathrm{RBE}$ cells. Then, the authors analyzed the effects of osthole on apoptosis following transfection. As depicted in Fig. 4D, the apoptosis rate was significantly decreased in cells transfected with WT-Akt and CA-Akt, especially the early apoptosis rate. The authors investigated the apoptosis-related protein levels in osthole-treated cells following transfection with WT-Akt and 

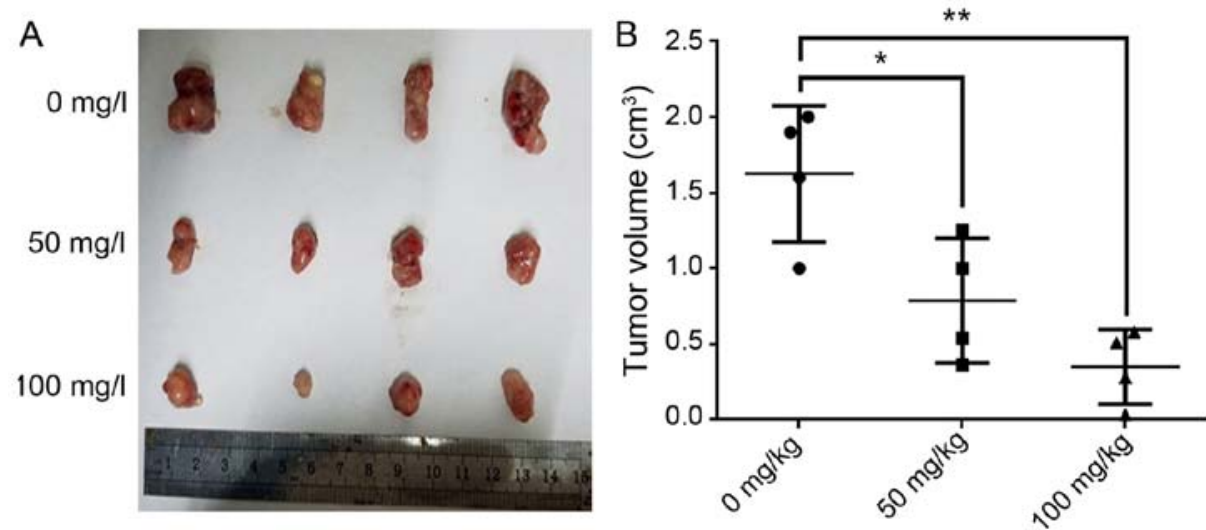

C
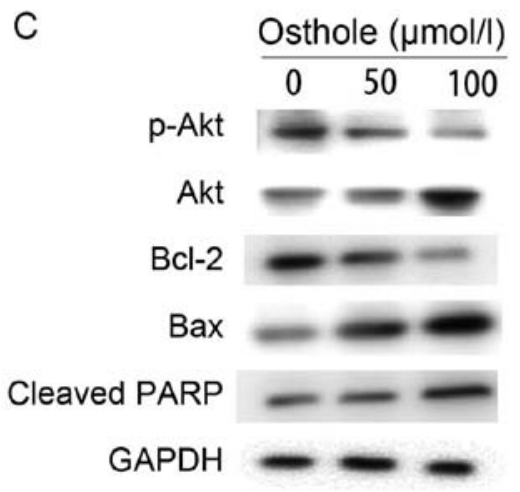

Figure 5. Osthole inhibits tumor growth in vivo. Mice were injected with corn oil (control group) or osthole (50 or $100 \mathrm{mg} / \mathrm{kg}$ ) every 2 days following injection with HCCC-9810 cells. (A) Tumors were excised from the animals and weighed. Images of 4 representative tumors from mice ( $\mathrm{n}=6$ ) in each group are presented to show the sizes of the resulting tumors. (B) Tumor volume was also measured. ${ }^{*} \mathrm{P}<0.05,{ }^{* *} \mathrm{P}<0.01$ vs. control. (C) Bcl-2, Bax, p-Akt, Akt and cleaved-PARP expression levels were analyzed using western blot analysis.

CA-Akt and observed that the level of Bcl-2 was significantly increased while the level of Bax was decreased. These findings suggested that the overexpression of WT-Akt and CA-Akt can inhibit the apoptosis of HCCC-9810 and RBE cells induced by osthole.

Therefore, the authors concluded that osthole induces mitochondria-dependent apoptosis via the Akt signaling pathway. Furthermore, modulation of the Akt signaling pathway may account for the anti-proliferative effect of osthole.

Osthole inhibits tumor growth in vivo. To explore the anticancer effect of osthole in vivo, HCCC-9810 cells were injected into the flanks of nude mice. The mice were injected with corn oil (control group) or osthole (50 or $100 \mathrm{mg} / \mathrm{kg}$ ) every 2 days. As presented in Fig. 5A and B, the tumor size and tumor weight were significantly lower in mice treated with osthole. Moreover, the authors investigated apoptosis-related protein expression levels using western blot analysis. Bcl-2 and p-Akt expression levels were strikingly lower and Bax and cleaved-PARP expression levels were significantly higher in osthole-treated groups than in the control group (Fig. 5C). These results are consistent with the in vitro effects of otshole on ICC cells.

\section{Discussion}

ICC is a malignant tumor for which surgical resection is the only effective treatment option, and its prognosis remains very poor. Therefore, it is essential to identify novel effective treatments for ICC. Several studies have reported that certain natural chemicals and compounds exert anticancer effects on a wide variety of tumor types $(19,20)$. Osthole is a natural coumarin isolated from Umbelliferae plant monomers, and previous studies have reported that it has anticancer effects in cancers such as glioma, colorectal cancer and lung cancer (21-24). However, there have been no studies evaluating the anticancer effects of osthole in ICC. In the present study, the authors indicated that osthole inhibited ICC cell proliferation both in vivo and in vitro. Thus, they suggested that osthole may represent a new adjuvant therapy that can improve the prognosis of ICC patients. In addition, the expression of apoptosis-related proteins was assessed using western blot analysis, and the results were in accordance with in vitro assays.

In the study, the effect of osthole on apoptosis in ICC cells was evaluated using Hoechst 33342 staining and flow cytometry. Apoptosis is generally characterized by specific morphological changes (25), such as cell shrinkage and pyknosis. Compared with control cells, cells treated with osthole presented distinct morphological changes, such as chromatin condensation and fragmentation. Moreover, treatment of ICC cells with osthole significantly increased the proportions of cells in the early and late apoptosis stages in a dose-dependent manner. A recent study reported that osthole suppressed proliferation and accelerated the apoptosis of human glioma cells, which is consistent with the results of the present study (14).

The mitochondria-dependent apoptosis pathway is a major signaling pathway leading to apoptotic death in mammalian cells (26). The Bcl-2 family, comprised of anti-apoptotic 
proteins (Bcl-2, Bcl-xL and Mcl-1) and pro-apoptotic proteins (Bax, Bad and Bak), is an important regulator of mitochondrial function. The anti-apoptotic factor Bcl-2 has been shown to prevent apoptosis by forming a heterodimer with pro-apoptotic factors, such as Bax (27). Bax is a pro-apoptotic protein that translocates to the outer mitochondrial membrane and promotes permeabilization and the release of various apoptotic factors. The Bcl-2/Bax ratio is important for cell survival and death. A decreased Bcl-2/Bax ratio changes the symmetry of mitochondria, activates mitochondrial permeability transition pores, induces the loss of $\Delta \Psi \mathrm{m}$, releases cytochrome $c$ and induces formation of the apoptosome complex, which causes the cleavage of caspase- 9 and activation of caspase- 3 and PARP. In the present study, the authors found that Bax and cleaved-PARP protein levels were significantly increased, while the level of $\mathrm{Bcl}-2$ was decreased, in response to osthole treatment both in vitro and in vivo. The expression levels of cleaved caspase- 3 and -9 were also significantly increased in osthole-treated cells, while the levels of caspase-3 and -9 were unchanged. Moreover, osthole treatment of ICC cells reduced $\Delta \Psi \mathrm{m}$ in a dose-dependent manner. Taken together, the findings suggested that cellular apoptosis in ICC cells mediated by osthole in vivo and in vitro was dependent on the mitochondriaapoptosome-mediated intrinsic pathway of apoptosis.

The PI3K/Akt signaling pathway has been shown to mediate a protective effect in tumor cells (28). Akt is a key downstream kinase of PI3K, and activation of the Akt pathway is a major mediator of cell proliferation, growth, survival and angiogenesis in various cancers such as lung cancer, breast cancer and gastric cancer (29-31). Previous studies have reported that osthole exerts anticancer effects by inhibiting the PI3K/ Akt pathway in various cancers. For example, in lung cancer, osthole induces $\mathrm{G} 2 / \mathrm{M}$ arrest and apoptosis by modulating the PI3K/Akt pathway (32). Osthole also exhibits anticancer properties in rat glioma by inhibiting the PI3K/Akt pathway and MAPK signaling pathways (22). Therefore, the authors assessed the anticancer effects of osthole by focusing on the PI3K/Akt pathway in ICC cancer cells. In the present study, the expression levels of p-Akt and PI3K were significantly decreased following treatment with osthole. Moreover, transfection with WT-Akt and CA-Akt abolished osthole cytotoxicity and reduced the apoptosis rate induced by osthole. Furthermore, the expression level of Bcl-2 was significantly increased, while the Bax level was decreased, following transfection. These results suggested that the PI3K/Akt pathway serves an important role in the mechanism of osthole-mediated suppression of proliferation and induction of apoptosis in ICC cells.

Overall, the present findings demonstrated that osthole can suppress proliferation and induce apoptosis in ICC cells both in vivo and in vitro. Moreover, the intrinsic mitochondrial pathway and Akt pathway are involved in osthole-induced apoptosis. Thus, the present study provides evidence supporting osthole as a potential therapeutic agent for the treatment of ICC.

\section{Acknowledgements}

The authors would like to thank Professor Yingbin Liu (Department of Cardio-Thoracic Surgery, Xinhua Hospital affiliated to Shanghai Jiao Tong University School of Medicine) for providing necessary materials, advice of great value and inspiration of new ideas. The authors would also like to thank the Institute of Biliary Tract Disease of Shanghai (Shanghai, China) for providing instruments. Thanks is also extended to all researchers working together for their invaluable assistance. The present study was funded by Anhui Provincial Natural Science Foundation (grant no. 1308085MH133)

\section{References}

1. Khan SA, Thomas HC, Davidson BR and Taylor-Robinson SD: Cholangiocarcinoma. Lancet 366: 1303-1314, 2005.

2. McLean L and Patel T: Racial and ethnic variations in the epidemiology of intrahepatic cholangiocarcinoma in the United States. Liver Int 26: 1047-1053, 2006.

3. Khan SA, Emadossadaty S, Ladep NG, Thomas HC, Elliott P, Taylor-Robinson SD and Toledano MB: Rising trends in cholangiocarcinoma: Is the ICD classification system misleading us? J Hepatol 56: 848-854, 2012.

4. Dhanasekaran R, Hemming AW, Zendejas I, George T, Nelson DR, Soldevila-Pico C, Firpi RJ, Morelli G, Clark V and Cabrera R: Treatment outcomes and prognostic factors of intrahepatic cholangiocarcinoma. Oncol Rep 29: 1259-1267, 2013.

5. Aishima S and Oda Y: Pathogenesis and classification of intrahepatic cholangiocarcinoma: Different characters of perihilar large duct type versus peripheral small duct type. J Hepatobiliary Pancreat Sci 22: 94-100, 2015.

6. Hwang S, Lee YJ, Song GW, Park KM, Kim KH, Ahn CS, Moon DB and Lee SG: Prognostic impact of tumor growth type on 7th AJCC staging system for intrahepatic cholangiocarcinoma: A single-center experience of 659 cases. J Gastrointest Surg 19: 1291-1304, 2015.

7. Tabrizian P, Jibara G, Hechtman JF, Franssen B, Labow DM, Schwartz ME, Thung SN and Sarpel U: Outcomes following resection of intrahepatic cholangiocarcinoma. HPB Oxf 17: 344-351, 2015.

8. Bao R, Shu Y, Wu X, Weng H, Ding Q, Cao Y, Li M, Mu J, Wu W, Ding $\mathrm{Q}$, et al: Oridonin induces apoptosis and cell cycle arrest of gallbladder cancer cells via the mitochondrial pathway. BMC Cancer 14: 217, 2014.

9. Xiong J, Su T, Qu Z, Yang Q, Wang Y, Li J and Zhou S: Triptolide has anticancer and chemosensitization effects by down-regulating Akt activation through the MDM2/REST pathway in human breast cancer. Oncotarget 7: 23933-23946, 2016.

10. Li M, Zhang F, Wang X, Wu X, Zhang B, Zhang N, Wu W, Wang Z, Weng H, Liu S, et al: Magnolol inhibits growth of gallbladder cancer cells through the p53 pathway. Cancer Sci 106: 1341-1350, 2015.

11. Luszczki JJ, Andres-Mach M, Cisowski W, Mazol I, Glowniak K and Czuczwar SJ: Osthole suppresses seizures in the mouse maximal electroshock seizure model. Eur J Pharmacol 607: 107-109, 2009.

12. Zhang Q, Qin L, He W, Van Puyvelde L, Maes D, Adams A Zheng $\mathrm{H}$ and De Kimpe N: Coumarins from Cnidium monnieri and their antiosteoporotic activity. Planta Med 73: 13-19, 2007.

13. Liu J, Zhang W, Zhou L, Wang X and Lian Q: Anti-inflammatory effect and mechanism of osthole in rats. Zhong Yao Cai 28: 1002-1006, 2005.

14. Lin K, Gao Z, Shang B, Sui S and Fu Q: Osthole suppresses the proliferation and accelerates the apoptosis of human glioma cells via the upregulation of microRNA-16 and downregulation of MMP-9. Mol Med Rep 12: 4592-4597, 2015.

15. Wang L, Peng Y, Shi K, Wang H, Lu J, Li Y and Ma C: Osthole inhibits proliferation of human breast cancer cells by inducing cell cycle arrest and apoptosis. J Biomed Res 29: 132-138, 2015.

16. Wen YC, Lee WJ, Tan P, Yang SF, Hsiao M, Lee LM and Chien MH: By inhibiting snail signaling and miR-23a-3p, osthole suppresses the EMT-mediated metastatic ability in prostate cancer. Oncotarget 6: 21120-21136, 2015.

17. Lu W, Cao Y, Zhang Y, Li S, Gao J, Wang XA, Mu J, Hu YP, Jiang L, Dong P, et al: Up-regulation of PKM2 promote malignancy and related to adverse prognostic risk factor in human gallbladder cancer. Sci Rep 6: 26351, 2016.

18. Wani ZA, Guru SK, Rao AV, Sharma S, Mahajan G, Behl A, Kumar A, Sharma PR, Kamal A, Bhushan S, et al: A novel quinazolinone chalcone derivative induces mitochondrial dependent apoptosis and inhibits PI3K/Akt/mTOR signaling pathway in human colon cancer HCT-116 cells. Food Chem Toxicol 87: 1-11, 2016. 
19. Lu DY, Chang CS, Yeh WL, Tang CH, Cheung CW, Leung YM, Liu JF and Wong KL: The novel phloroglucinol derivative BFP induces apoptosis of glioma cancer through reactive oxygen species and endoplasmic reticulum stress pathways. Phytomedicine 19: 1093-1100, 2012.

20. Tsai CF, Yeh WL, Huang SM, Tan TW and Lu DY: Wogonin induces reactive oxygen species production and cell apoptosis in human glioma cancer cells. Int J Mol Sci 13: 9877-9892, 2012.

21. Zhang L, Jiang G, Yao F, He Y, Liang G, Zhang Y, Hu B, Wu Y, $\mathrm{Li} \mathrm{Y}$ and Liu H: Growth inhibition and apoptosis induced by osthole, a natural coumarin, in hepatocellular carcinoma. PLoS One 7: e37865-e37865, 2012.

22. Ding D, Wei S, Song Y, Li L, Du G, Zhan H and Cao Y: Osthole exhibits anticancer property in rat glioma cells through inhibiting PI3K/Akt and MAPK signaling pathways. Cell Physiol Biochem 32: 1751-1760, 2013.

23. Liu LY, Huang WJ, Lin RJ, Lin SY and Liang YC: $\mathrm{N}$-Hydroxycinnamide derivatives of osthole presenting genotoxicity and cytotoxicity against human colon adenocarcinoma cells in vitro and in vivo. Chem Res Toxicol 26: 1683-1691, 2013

24. Yang HY, Hsu YF, Chiu PT, Ho SJ, Wang CH, Chi CC, Huang YH, Lee CF, Li YS, Ou G, et al: Anticancer activity of an osthole derivative, NBM-T-BMX-OS01: Targeting vascular endothelial growth factor receptor signaling and angiogenesis. PLoS One 8: e81592, 2013.

25. Häcker G: The morphology of apoptosis. Cell Tissue Res 301: $5-17,2000$.
26. Elmore S: Apoptosis: A review of programmed cell death. Toxicol Pathol 35: 495-516, 2007.

27. Wang J, Lu ML, Dai HL, Zhang SP, Wang HX and Wei N Esculetin, a coumarin derivative, exerts in vitro and in vivo antiproliferative activity against hepatocellular carcinoma by initiating a mitochondrial-dependent apoptosis pathway. Braz J Med Biol Res 48: 245-253, 2015.

28. Fresno Vara JA, Casado E, de Castro J, Cejas P, Belda-Iniesta C and González-Barón M: PI3K/Akt signalling pathway and cancer. Cancer Treat Rev 30: 193-204, 2004.

29. Shrivastav A and Murphy L: Interactions of PI3K/Akt/mTOR and estrogen receptor signaling in breast cancer. Breast Cancer Manag 1: 235-249, 2012.

30. Shi L, Wang L and Wang X: Osteopontin induces epithelial-to-mesenchymal transitions in human lung cancer cells via PI3K/Akt and MEK/Erk1/2 signaling pathways. Chest 149: A332-A332, 2016

31. Riquelme I, Tapia O, Leal P, Sandoval A, Varga MG, Letelier P, Buchegger K, Bizama C, Espinoza JA, Peek RM, et al: miR-101-2, miR-125b-2 and miR-451a act as potential tumor suppressors in gastric cancer through regulation of the PI3K/AKT/mTOR pathway. Cell Oncol (Dordr) 39: 23-33, 2016.

32. Xu X, Zhang Y, Qu D, Jiang T and Li S: Osthole induces G2/M arrest and apoptosis in lung cancer A549 cells by modulating PI3K/Akt pathway. J Exp Clin Cancer Res 30: 33, 2011. 